\title{
A Pragma-Semiotic Analysis of Emoticons in Social Media
}

\author{
Ali M. Al- Mjdawi \\ Department of English, College of Education and Humanities, Wasit University, Iraq \\ E-mail: agharab@uowasit.edu.iq \\ Saja I. Jabi (Corresponding author) \\ Department of English, College of Education and Humanities, Wasit University, Iraq \\ E-mail: sajaalrekabi@gmail.com
}

Received: October 28, 2020 Accepted: December 9, 2020 Published: December 11, 2020

doi:10.5296/elr.v6i2.17887

URL: https://doi.org/10.5296/elr.v6i2.17887

\begin{abstract}
Since the early days of the internet, researchers investigate in the peculiar use of language in social media. One distinctive feature is the use of emoticons as a way to express users' emotions in digital settings. In spite of their popularity, researches on emoticons are still in its infancy. This research identifies the pragmatic and semiotic functions of emoticons in social media following qualitative and quantitative methods for analysing data. The corpus of this study are collected from Twitter and YouTube. The analysis of data follows the Three Levels Pragma-Semiotic Model. Quantitative analysis shows that the usage of emoticons with text appears to improve the expressivity and an overall sentiment scores of positive and negative opinions relatively more than the neutral opinions. It also shows that emoticons are preferably used with text or other emoticons. From the qualitative analysis, the current study has made visible the practices of using emoticons in social media.
\end{abstract}

Keywords: Social media, Emoticons, Pragmatics, Semiotics, CMC, FTF

\section{Introduction}

Human beings commonly use social media to share information as well as to express emotions. They can express them either verbally by using speech or non-verbally by using body language, facial expression, gesture and so on. Emoticons as its name offers, which is a blend of emotion and icons, they are related to expressing emotion. During the 20th century, computer mediated communication (CMC) has been developed rapidly. With the expansion 
of social media usage; emoticons become a trending topic in technological researches about digital communication.

Most people face difficulties concerning explaining meaning of text messages. Thus, why people started to use emoticons as a new language in order to humanise their text messages. In every day conversation people often need to use non-verbal cues to clarify the meaning of what they said. Within social media emoticons represent the non-verbal codes that people need to interpret their text messaging.

All of massaging applications used in smartphones have emoticons. In the past, emoticons had a symbolic form as ":)" that means happy expression, but nowadays emoticons develop into different figures and various shapes like "우, (3), and colours" despite such differences, emoticons have the same universal function of expressing the emotions of the users.

In spite of the fact that emoticons and their meaning, function, and effect are investigated vastly in previous researches; there is incompatibility among researches on functions that emoticons can perform and on the role played by context in their usage. This study will fill this gap by clarifying the effect of emoticons on people's responses to some public posts on twitter and YouTube.

\subsection{Questions of the Study}

Tian, Galery, Dulcinati, Molimpakis and Sun (2017) affirm that "Although the polarity of emoticons frequently mismatch the polarity of the accompanying linguistic text or even the entire message, little has been done to analyse the nature of these icons"(p. 2). Despite their popularity, little research has been done specifically on emoticons (Nishimura, 2015). Hence, this study will answer the following questions:

1). How can recipients make a link between an emoticons and a linguistic text? And how does context affect meaning and function of emoticons?

2). What are the main functions of emoticons?

3). Do emoticons have a positive, negative or both impressions? And does a text with emoticons has a different meaning from the text without emoticons?

\section{Literature Review}

This section presents an overview of literature about pragmatics and semiotics, it shows the important definitions and types of emoticons, finally. It ends with giving a background knowledge of social media.

\subsection{Pragmatics and Semiotics: An Overview}

\subsubsection{Pragmatics}

As reasoned by Crystal (2010), "pragmatics is not a coherent field of study since it overlaps with many other linguistic areas and consists of various different aspects of language use" ( $p$. 124). According to the new lexicon Webster's encyclopedia dictionary of the English language (1993), pragmatics is "the science of relationship between symbols, their interpretation and, users"(p. 197). While Leech (1983) saw pragmatics as "the study of meaning in relation to speech situations" (p. 6). Wales (1989) considered it basically as the 
"study of language use" (p. 386).

Yule (1996) opined that pragmatics can be defined from four perspectives: He asserts that "Pragmatics is the study of speaker meaning", "Pragmatics is the study of contextual meaning", "Pragmatics is the study of how more gets communicated than is said", and "Pragmatics is the study of the expression of relative distance" (p. 3 ).

Based on the definitions above; Adegbija (1999) maintained that pragmatics takes cognizance from the message being communicated and the speech act being performed, the participants involved, their interpretation, knowledge of the world and the impacts of these on their interaction, what they have taken for granted as a part of the context (or the presuppositions), the deductions they make on the basis of the context, what is implied by what is said or left unsaid, the impacts of the non-verbal aspects of interaction on meaning.

\subsubsection{Semiotics}

Bignell quoted that Semiotics (or semiology) is one of the most powerful and influential ways of thinking about media. The name semiotics and semiology derives from the ancient Greek word "semeion", which means "sign". Semiotics is a way of analysing meanings by looking at the signs (like words, pictures, symbols etc.) which communicate meaning. There are two rubrics of studying semiotics: One being general study of "semiosis" which comes under the rubric of "biosemiotics". The other being study of human "semiosis", in specific cultural contexts, covered under cultural semiotics (Bignell, 2002, pp. 1-3).

Semiotics is the study of signs and signifying practices. A sign can be defined, principally, as any entity (words, images, objects.) that refers to something else. Semiotics studies how this referring results from previously established social convention (Eco, 1976). Signifying practices simply refer to how, rather than what, meaning is produced. Finally, the social convention which links signs with meanings is called a code (Potts, 1996).

\subsubsection{The Metalanguage of Pragma-Semiotics}

A metalanguage is conceived to be that language which gives or presents or assigns terms for the analysis of an object-language. It is, according to the Oxford English dictionary (1989), a formal language system describing language or a linguistic source. Put differently, "it is a sign-system developed to talk about another sign system as content, or a higher level language to talk about another language (object-language)" (Wales, 1989, p. 294).

\subsection{Emoticons}

An emoticon is a visual element embedded in text in digital communication, most typically faces created by combining punctuation and typographic symbols to express a notion, for example, happy :-), sad : -(, laughter :-D and so on. There are four types of emoticons according to Nishimura (2015)

(1) Kaomoji or typographic face marks, for example $\left({ }^{\wedge}{ }_{-}\right)$'smile' and $\left(>_{-}<\right)$'embarrassment'. They are equivalent to English-language emoticons in terms of formation and facial representations, though horizontal. Japanese kaomoji are elaborate combinations of symbols that express emotions, actions and greetings: Kaomoji websites offer further subtle distinctions for users.

(2) Kigou or non-linguistic symbols, for example, $5 \delta \odot$. They often appear at the end of a 


\section{Macrothink}

sentence and may function as punctuation, but with more visual impact and added meaning. The role of kigou as emoticon is to minimize dry, businesslike atmosphere/tone of the message.

(3) Kanji emoticon, where an ideographic kanji enclosed by parentheses gives additional information about the writer's feelings based on the meaning of the kanji, for example, (笑) “laughter” and (怒) “anger.

(4) Emoji or colorful graphics embedded in lines of text, which represent not only faces but also objects, ideas and more. Some are animated, for example, a beating heart, blinking eyes or shining stars. They are used mostly for decorative purposes, but also function indexically,

and serve lexical purposes by replacing text, for example, the emoji

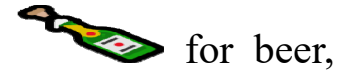
instead of the word beer.

\subsection{Social Media}

Social media are computer tools that allow people to share or exchange information, ideas, images, videos and even more with each other through a particular network. Social media can be classified into the following categories: (a) Social networking sites; they provide a web-based platform for building social networks or social relations amongst people, e.g., shared interests or activities. They provide a means to interact over the internet, e-mail and now even the mobile phones.(b) Blogs (derived from the word weblog) are an online journal where an individual, group, or corporation presents a record of activities, thoughts, or beliefs. Content generating and sharing sites; these sites serve as sources of information for various topics. (c)User appraisal sites which serve as a platform for appraisals of various products and services (Baruah, 2012).

\section{Methodology}

\subsection{The Pragma-Semiotic Model Approach}

The theoretical framework of analysis adopted for this present study is the pragma-semiotic model of communication. The model shows the three levels of communication, the addresser, the address/message and the addressee or the physical, psychological and practical stages respectively. There is a continuum among the three levels as physical actions are taken to generate certain psychological interpretation which results to practical reaction. The Pragma-Semiotic model with reference to the goal of the present study is given and described as follows: 


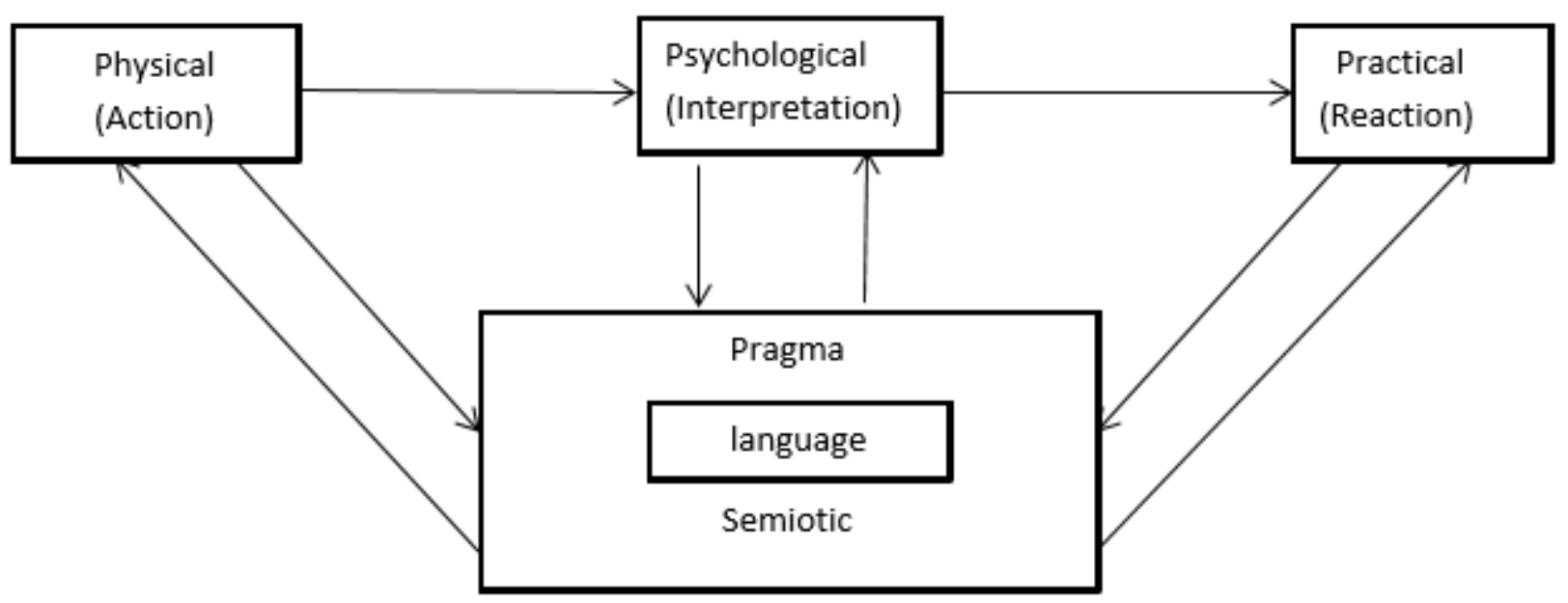

Figure 1. The Three levels Pragma-Semiotic Model from Achi, S. (2010). Third international conference on advances in computer- human interaction, IEEE computer society (pp.1-6).

Washington: DC

\subsection{Emoticon Research Methods}

Emoticon research has been conducted utilising a wide variety of methodologies. For example, Walther and D'Addario (2001) conduct a laboratory experiment utilising manipulated hypothetical messages. These messages are constructed to be positive or negative and either include an emoticon or do not. After reading the message, participants filled out a questionnaire to assess their impressions. This type of methodology is recurrent throughout the emoticon literature.

Researchers have also examined naturally occurring conversations within assorted computer mediated communication (CMC) environments. Darics (2010) utilises an interactionally grounded approach and analyses the naturally occurring text-based interactions of a virtual team. She reviews the instant messenger chat transcripts recorded from actual conversations. As such, she is able to explore how emoticons are utilised in workplace-talk. Other studies use similar processes and gather data from mediated conversations. These dialogues are often found online via blogs, chat rooms, newsgroups, message boards and instant messages. Lastly, some reports rely on interpretative methods and draw from literature inferences and researcher observations.

This study is conducted through a mixed method approach. It involves a mixture of a qualitative and quantitative method/s. Creswell (2014) presents the terms qualitative, quantitative and mixed methods as overarching research methods that differ in their basis. In qualitative research studies, the researcher focuses on studying meaning that is associated to a particular social problem. According to Denzin and Lincoln (1994), in qualitative research, the researcher is not concerned with quantifiable data, instead, s/he studies "things in their natural settings, attempting to make sense of, or interpret, phenomena in terms of the meanings people bring to them" (p. 2). On the other hand, quantitative research includes the use of statistical procedures in analysing numerical data to test objective theories. So, the integration of those both methods can be used to strengthen and enrich the analysis and 
findings of the research as well. Finally, to ensure objectivity, mixed method is necessary to avoid any personal taste (Devellis, 1991).

Ethnography approach is adopted within qualitative analysis as context and culture are the main focus of the qualitative inquiry. Correlational approach is adopted within quantitative analysis as the relationship between two or more variables using statistical data is the basic focus in this method (Creswell, 2014).

\subsection{Data Collection and Description}

The data consist of 27 tweets and 33 comments, they are selected from tweeter and you tube respectively. The sampling are collected between 1October 2019 to 1may 2020. As discussed before that there are four types of emoticons. In this study, the kind of emoticons used as data are the emoji and kamoji. This dataset provides a recent ranking of how often each emoticon is used.

The study deals with two different language comments and tweets (Arabic and English). About different topics such as healthy or medical topics, political and national issues, religious and human rights issues, and sports. Those, topics which are trending during this period. They are useful to make a comparison in the use of emoticons. They figure out the different opinions and beliefs about the selected topics. They help us to discover the effect of context in the use of emoticons. The following table shows an examples about the data of this research.

\section{Data Analysis}

This section is concerned with the analysis of tweets and comments which are selected from Twitter and YouTube of English and Arabic languages. This chapter is divided into two parts: the qualitative and the quantitative analysis of the corpus. The first part deals with the pragmatic functions of emoticons and the semiotics of emoticons. the second part explains data distribution and frequency. In order to achieve valid and reliable results the researcher uses the three levels pragma-semiotic model from Achi, (2010).

\subsection{Qualitative Analysis}

Text 1: BBC.( 2020, Feb 28). "poor Turkish jihadi soldiers '̂े"'[comment, male]. You Tube

The commenter is clrearly expressing his point of veiw about turkish soldiers. Looking at the verbal contents of the comment, it can be seen that the commenter is stating the act of moping and feeling down. However, face with tears of Joy emoticon in this situation is switching the utterance from being interpreted as a sympathy with turkish solidiers, to simply a state of making fun. At the same time the commenter emploies this emoticon to lessening the negativity of the linguistic contents of the comment. Therefore, although positive emoticons coupled with negative verbal messages convey less negativity, the overall sentiments are determined by the verbal part, and are still negative. 
Table 1. Analysis of Emoticons of Text (1)Following Achi's Model

\begin{tabular}{llll}
\hline Emoticons & $\begin{array}{c}\text { Physical } \\
\text { addresser }\end{array}$ & $\begin{array}{l}\text { the } \\
\text { address }\end{array}$ & $\begin{array}{l}\text { Psychological } / \text { the } \\
\text { addressee }\end{array}$ \\
\hline Text 1 & laughing so hard & mitigation & Informative effect \\
\hline
\end{tabular}

Text 2: WP.(2020, MAR 14). "it was conspiracy theory when we were saying the mass graves in china, now Washington post publishes and it's real news.

[comment, male]. You Tube

Arguably, one face with rolling eyes has the same meaning which is disapproval, frustration, or boredom. Tone varies, including playful, sassy, resentful, and sarcastic, as if saying Yeah, whatever. But three probably make it stronger. With regards to the sentiment effect, this instance has a negative theme as it has negative words like 'conspiracy theory and mass graves'. Alternatively, face with rolling eyes emoticon belongs to the negative emoticons since one of its meaning is disapproval. Hence, Similar to positive emoticon on a plain positive message, negative emoticons also do not have sentiment effects on a plain negative message.

Table 2. Analysis of Emoticons of Texts (2)Following Achi's Model

\begin{tabular}{lllll}
\hline Emoticons & $\begin{array}{c}\text { Physical } \\
\text { addresser }\end{array}$ & the $\begin{array}{l}\text { Psychological } \\
\text { address }\end{array}$ & $\begin{array}{l}\text { Practical the } \\
\text { addressee }\end{array}$ \\
\hline Text 2 & Disapproval & Marker of emphasis & informative effect \\
\hline
\end{tabular}

Text 3: Hadi, Ahmad. (2020, Apr 27). “중 OMG THIS MAKES ME LAUGH SOOO

\section{HARD 중" [comment, female]. You Tube}

Here, the commenter writes in all-caps, which, if done purposefully, could express excitement. She uses the intensifying adverb "so" with a double "o" to translate expressive intonation. She also uses the shortened form OMG, which is the acronym for "Oh my god", a form that quintessentially expresses a high degree of surprise or excitement. Last but not least, she utilises the laughter emoticon 25 twice, at the beginning and the end of the message. Framing the message with this affective emoticon is a form of emphasis and possibly shows that this affective stance concerns the whole of the message not just an element of it. As in previous examples, there are no significant difference between the plain positive verbal message and the combinations of the message with a positive emoticon, in terms of mean sentiment. 


\section{Macrothink}

Table 3. Analysis of Emoticons of Text(3)Following Achi's Model

\begin{tabular}{lllll}
\hline Emoticons & $\begin{array}{c}\text { Physical } \\
\text { addresser }\end{array}$ & $/$ the $\begin{array}{l}\text { Psychological } / \text { the } \\
\text { address }\end{array}$ & $\begin{array}{l}\text { Practical } \\
\text { addressee }\end{array}$ \\
\hline Text 3 & $\begin{array}{l}\text { Happiness } \\
\text { excitement }\end{array}$ & or $\begin{array}{l}\text { Marker of emphasis } \\
\& \text { intensifier }\end{array}$ & $\begin{array}{l}\text { Influencing, } \\
\text { challenging effect }\end{array}$
\end{tabular}

In cases like the ones studied above, emoticons play a role that is comparable to that of intensifiers of all kinds. They are intensifiers of their own and, just as intensifiers, only make sense when used alongside another unit, which is often verbal and bears the propositional content of the message. So, again, emoticons can't be opposed to linguistic cues but seem to rightly belong to them, far from being mere non-verbal cues. However, this is not true of all emoticons uses. In fact, in the set of data studied, two uses of emoticons and seem to attach them to non-verbal cues.

Text 4: BBC. (2020, Feb 28). "The UN is a paper Tiger. NATO is a weekend sports club. Every one hides behind lawyers. Planet earth, safe in their hand "[comment, male]. You tube

The final utterance "Planet earth, safe in their hand informative statement, but it has also pragmatic implications. The utterance may be perceived as a correction or even as an accusation. The emoticon functions as a softener, which downgrades the illocutionary force in the commenter's correction. It contributes to softening the correction, and can even be interpreted as a humoristic comment. The emoticon serves to limit the negative implications of the utterance and to foreground the positive implications.

Table 4. Analysis of Emoticons of Text (4) Following Achi's Model

\begin{tabular}{|c|c|c|c|}
\hline Emoticons & $\begin{array}{l}\text { Physical / the } \\
\text { addresser }\end{array}$ & $\begin{array}{l}\text { Psychological / the } \\
\text { address }\end{array}$ & $\begin{array}{l}\text { Practical } \\
\text { addressee }\end{array}$ \\
\hline Text 4 & $\begin{array}{l}\text { conveys a sense of } \\
\text { fun, excitement }\end{array}$ & $\begin{array}{l}\text { softening } \\
\text { correction }\end{array}$ & $\begin{array}{l}\text { Influencing, urging } \\
\text { effect }\end{array}$ \\
\hline
\end{tabular}

Text 5: BLACKBINK.(2020, Apr 8). "I am happy when BP( $R * J i-L \bullet J e$ ) is happy ", [comment, female]. You tube

Let us start with the most easily decipherable emoticons in the text. First, the user is a speaker of English, not only because the verbal title of the passage is "I am happy when BP is happy" but also because: (a) Its layout from left to right and up-down, is identical to alphabetically constructed texts in that language, and (b) many of the symbols are clearly allusive to any English-speaking culture, including the symbol of flowers. In order to be able to encode the 
cods of these emoticons, you should know that this commenter is a fandom of the Korean "black pink" band: This band consists of four members (Rose, Jisoo, Lalisa and Jennie). If you know the members of this band then you can easily realize that the commenter uses the flowers to refer to them but why he use different types of flowers? the commenter use A rosette flower-shaped * with the firs letter "R" from Rose's name to stand for Rose because her name is rose. Secondly, the user uses a blossom flower with the first-two letters "JI" from Jisoo's name to refer to Jisoo because of the fact that she is the cutest, calmer and the most beautiful member among her friends in the group, and as is known for all the white color stands for beauty and innocence. Thirdly, the commenter uses Sunflower with the first letter " $L$ " of lalisa's name to represent 'lalisa' since she has a yellow hair in addition to that, the Sunflower is associated with summer (season of activity) and lalisa is an active girl. Fourthly, the writer uses a red flower with the first two letters "Je" of Jenie's name to stand for her, since Jenie is more attractive girl among her friends. Another emoticon has been used by the commenter is a classic love heart emoticon used for expressions of love, this usage confirms the researcher's words when she says that the commenter is a fandom. In addition to the linguistic content of the comment such as "I am happy when BP (R Ji L Je) is happy", also confirms this. The comment designer uses positive emoticons to represent her idols. This means that the sentiment of those emoticons stay the same in this comment.

Table 5. Analysis of Emoticons of Text (5)Following Achi's Model

\begin{tabular}{|c|c|c|c|}
\hline Emoticons & $\begin{array}{l}\text { Physical / the } \\
\text { addresser }\end{array}$ & $\begin{array}{l}\text { Psychological / the } \\
\text { address }\end{array}$ & $\begin{array}{l}\text { Practical } \\
\text { addressee }\end{array}$ \\
\hline \multirow[t]{5}{*}{$\begin{array}{l}\text { Text } \\
5\end{array}$} & $\begin{array}{l}\text { A rosette } \\
\text { flower-shaped }\end{array}$ & $\begin{array}{l}\text { stand for Rose( a girl's } \\
\text { name ) }\end{array}$ & $\begin{array}{l}\text { Informative, } \\
\text { persuasive effects }\end{array}$ \\
\hline & a blossom flower & refer to Jisoo & $\begin{array}{l}\text { Informative, } \\
\text { persuasive effects }\end{array}$ \\
\hline & Sunflower $\div$ & to represent lalisa & $\begin{array}{l}\text { Informative, } \\
\text { persuasive effects }\end{array}$ \\
\hline & a red flower & stand for Jenie & $\begin{array}{l}\text { Informative, } \\
\text { persuasive effects }\end{array}$ \\
\hline & $\begin{array}{l}\text { A classic love } \\
\text { heart }\end{array}$ & I love you & $\begin{array}{l}\text { Informative, } \\
\text { persuasive effects }\end{array}$ \\
\hline
\end{tabular}


Text 6: WP,(2020, MAR 14). "Burn the dead bodys, less diseases and takes up less land space@y $\Leftrightarrow 8 \theta$ "[comment, male]. You Yube

Text 7: futbolbible[@futbolbible].(2020,Apr 27). “football has no age. " [tweet]. Twitter

While some emoticon lexicon is limited in its nature, other characters are highly versatile.

How? In example (6), the commenter utilises the fire emoticon as a code for "heat". From the linguistic content of the code "Burn the dead bodys", as well as the compination of the fire emoticon with funeral urn $\Theta$ which used to hold the cremated ashes of the dead, the commenter by using the fire emoticon is intented to signify "the burn" meamimg. On the other hand, the fire emoticon can stand for the meanings of hotness(atractiveness), slang lit( awesome, exciting) as seen in eaxample(7). The researcher can assume from the lingyistic context "football has no age" that the user is excited about the football match nevertheless $\mathrm{s} / \mathrm{he}$ is an old person. Or the user is ecxited about watching an old person playing football in a good way. In short, emoticons are not used solely to embellish a text, but to convey a user's thoughts and ideas better by adding an extera dimention to a text. You tub's user uses a negative emoticons $\Theta$ in combaination with a negative message to send his/her intention. Similar to positive emojis on a plain positive message, negative emojis also do not have sentiment effects on a plain negative message. The analysis results show that the sentiment scores of these combinations are not significantly different from that of a plain message.

Table 6. Analysis of Emoticons of Texts(50,51) Following Achi's Mode

\begin{tabular}{lll}
\hline Emoticons & $\begin{array}{c}\text { Physical } / \text { the Psychological / the address } \\
\text { addresser }\end{array}$ & $\begin{array}{l}\text { Practical } \\
\text { addressee }\end{array}$ \\
Text 6 & Furn & $\begin{array}{l}\text { Influencing, } \\
\text { warning effects }\end{array}$ \\
Text 7 & Attractiveness and excitement & $\begin{array}{l}\text { Persuasive, } \\
\text { informative bodies } \\
\text { confusing effects }\end{array}$ \\
\hline
\end{tabular}


Text 8: Gurdian news,(2020, MAR 23). “please $2 \Rightarrow$

[comment, female], you tube

With the linguistic knowledge of syntax, researcher knows that compartive sentence is used to compare two people, ideas, or things. The first three emoticons $\Rightarrow$ first noun and the last two emoticons $=-2$ stand for the second noun; both of them are compared by an adjective "better". On the one side, The woman kneeling emoticon 2 in this comment refers to the noun "staying", the arrow emoticon interprets as the preposition "at" and the home emoticon is the first noun (N1) which in turn function as a subject. On the other side, face with head-bandage $\because$ conveys 'illness', and face with thermometer $\$ 2$ represents a 'hospital patient'. And this is a second noun (N2), that functions as an object to the comparative sentence. So the researcher can draws the comparative sentence as "staying at $\Rightarrow$ home $\mathrm{A}(\mathrm{N} 1$, subject) is better than being a hospital patient -2 (N2, object)". Therefore, the emoticon-constructed sentence, although conceptual, still has a basic verbal syntax guiding it: that is, the sentence layout from left to-right follows the syntax of English grammar. The positioning of ( $\Rightarrow$ ) to the left, as in a typical subject slot in a declarative sentence, assumes unconscious knowledge of how the actor-agent relation unfolds; indeed reversing the first and last emoticons would create a meaning dissonance or asymmetry. According to some cognitive linguists, this type of conceptual structure characterizes all of language, unconsciously. Now let us consider the sentiment of those emoticons. The first three emoticons consist of positive neutral $\Rightarrow$ and negative 2 emoticons. however, when they grouped together their icons changed to signify a positive noun. While on the last two emoticons are used to encoding a negative noun. The existence of the word 'better' to make comparison between two nouns as well as the inter text of the comment reinforce the researcher's analysis. 
Table 7. Analysis of Emoticons of Example (8) Following Achi's Mode

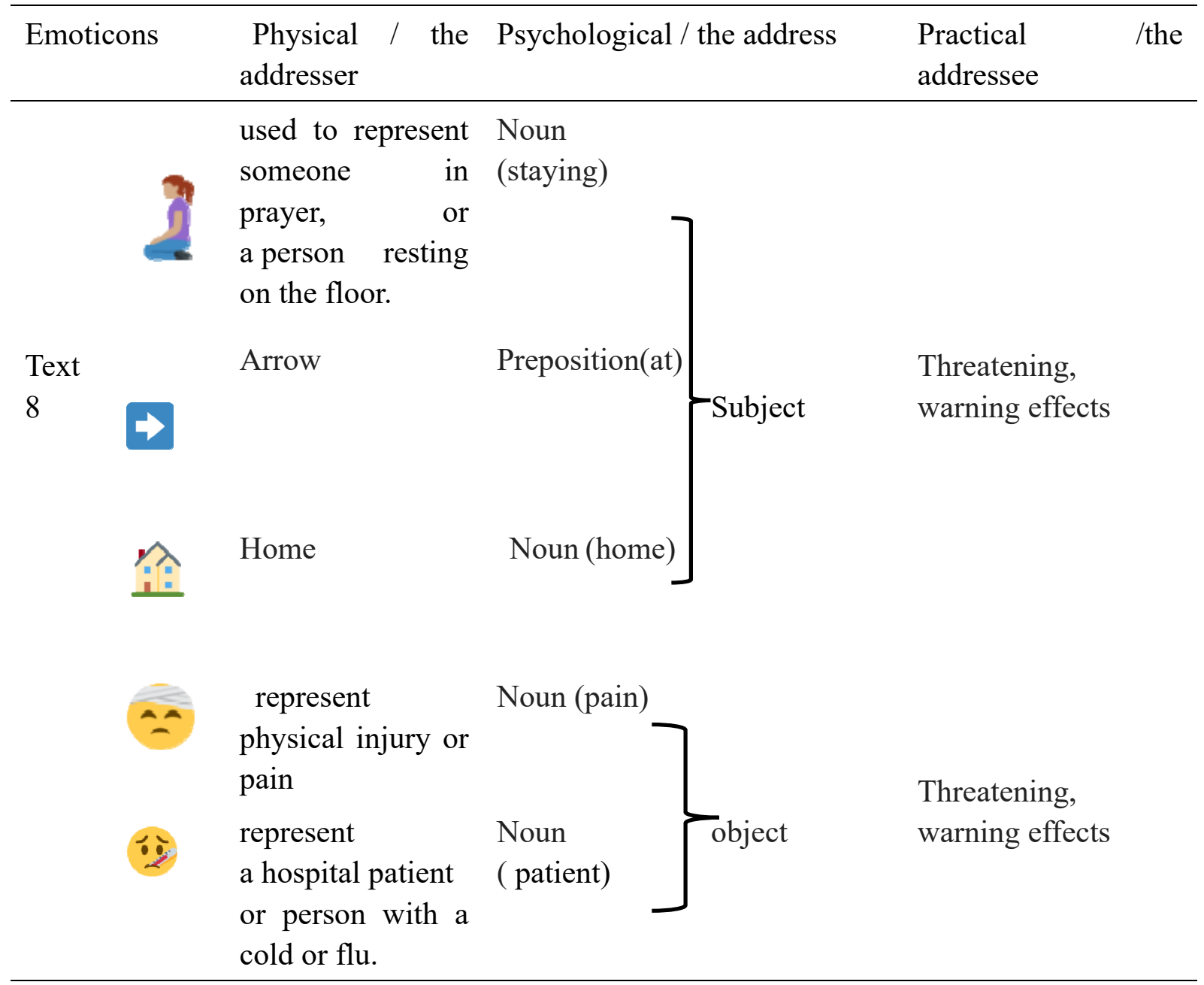

Text 9: UNFPA[@UNFPA]. (2020, May 9). "WHO \& UNFPA-Yemen partner with the support of UAE Aid to build the capacity of health systems and community-based services to ensure access and increased availability of emergency reproductive health services for women 우 "[tweet]. Twitter

Text 10: BBC,(2020, Feb 28). "“poor Syria people $\because$ Everybody come to them and do the sheet Syria became a place for war to USA, Turkey, Russia, EU and others. It's easy to talk about it when you are far from fire and death. sos $100 \%$ they are doing the war for money and political dominance look at this hypocrite attitude of the UN $\because \because$ "[ comment, female]. You Tube

Text 11:

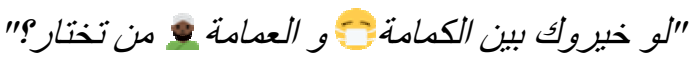
Mohammed.A.WAHAB[@Mohammed_wahab].(2020,.Apr 14). "if they make you to choose 
between face mask male], Twitter

Text 12:

and aleimamuh( islamic turban)

what will you choose?" [tweet,

باللاجئيين السورين

BBC NEWS يالعربي)( 2020, Oct 11) "North Korea threatens the world with nuclear weapons $\because$ And Turkey threatens Europe with Syrian refugees $\cdot$ "[comment, female].

\section{YouTube}

As it mentioned earlier that the model function refers to the use of emoticons for clarifying the text messages. As such, all the emoticons in the above examples $(9,10,11,12)$ have a model function but in different stratigies. In example (9) the user uses a woman with headscarf 2 emoticon to stat that $\mathrm{s} /$ he means a spisific type of woman which is a muslim woman. So s/he utilises it to expand the proposition of her/his tweet by adding a new information. If the redears look at the contents of the text in which this emoticon has been applied, ther is not any codes convey that the word woman is used to stand for a muslim woman except the emoticon. However, in example(10) the commenter employs seven kinds of emoticons for explaining her attitudes about varaints countries and orginasaitions. The first emoticon is frowning face $\because$ with the word "poor syria people", in order to say that she feels sad or disappointed about people who live in Syria. Then she uses a palming face emoticon $\mathcal{E}$, which is used to display frustration or embarrassment at the ineptitude of a situation that everyone comes to them and doing shit. From the content of the text, the commenter uses the fire emoticon to indicates "war" that caused by USA, turkey, Russia, EU and others. After that, the commenter uses two kinds of marks emoticons. ${ }^{505}$ SOS is the description for the distress signal in Morse Code. This emoticon means SOS or "emergency". And A hazard symbol for radiation or radioactivity. With the linguistic and the socio-political contexts, the researcher can impose that both emoticons indicate the seriousness of the situation and the necessity of international organizations intervening to stop the war there. She evaluates the

bearings of united nations by using $\because$ The hear no evil monkey and $\because$ The speak no evil monkey. Which means that the UN ignore those poor people in Syria because the war is far from their countries. So the researcher can generalises the idea that the user uses such emoticons to give her attitude by evaluating or commenting on situations. As a result, they all have modal functions. Let us move to example (11) in this tweet, the user uses two emoticons:

Face with medical mask $=$ after the word "medical mask" and a man wearing a

turban 2 emoticon after the word "aleimamuh"( a form of customary headwear worn by Muslims). Here, the emoticons have a model functions because they just used for the purpose 
of decoration, they do not add a new information or evaluating something, but they only illustrate the words fictitiously. At the end, the forth kind of model function exists in example(12), in which the emoticon used since there is a semantic redundancy between the text and an emoticons. the user in this comment compares between two types of threats by two countries. For each kind she utilises an emoticons that represent the degree of its inhumanity and brutality. The first threat is by north Korea which treats the world with nuclear weapons and its represented by a full moon face $\because$ and the second threat is by Turkey which threats Europe with Syrian refugees and it represented by a new moon face

The difference between these two emoticons lays in the colors. The first kind exemplifies with a white colors and the other one by a black one, because the first one is not insulting humanity. Concerning the sentiment of those emoticons, in example (9), tweeter's user uses a neutral emoticon ' (-), with a positive message for decreasing effects on the sentiment of the plain positive message. moving to example (10), the commenter utilises negative emoticons

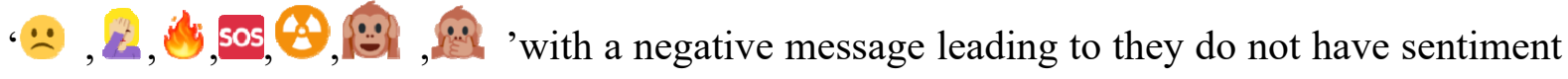
effects on a plain negative message. In example(11), the user uses a positive emoticon with a negative message so that the readers can decoding the message in a neutral or negative way. Lastly, in example (12), the commenter uses a neutral emoticon ' $\because$ ' with a positive message 'North Korea threatens the world with nuclear weapons'. What can be observed from this combaination is a neutral emojis are the most proper to express irony as well as they may introduce sarcasm to a plain positive message, and consequently, decrease the positivity. Move to part two of this comment, the user uses a negative emoticon ' $\because$, with a negative message 'Turkey threatens Europe with Syrian refugees'. The analysis results show that the sentiment scores of this combination is not significantly different from that of a plain message.

Table 8. Analysis of Emoticons of Texts (9.10.11.12) Following Achi's Mode

\begin{tabular}{llll}
\hline Emoticons & $\begin{array}{c}\text { Physical / the Psychological/the address } \\
\text { addresser }\end{array}$ & $\begin{array}{l}\text { Practical } \\
\text { addressee }\end{array}$ \\
\hline $\begin{array}{l}\text { Text } 8 \text { Arabic, Muslim } \\
\text { woman. }\end{array}$ & $\begin{array}{l}\text { Modal function \{expansion of Informative effect } \\
\text { the proposition(additional } \\
\text { information) }\}\end{array}$
\end{tabular}

Used to display Modal function \{expansion of Influncing effect sadness or the proposition(propositional 
disappointment

Text

10

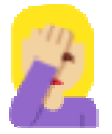

Used

n display frustratio embarrassment

Used to display war the

to

Modal function \{expansion of the proposition(propositional

or attitude, commenting )\}

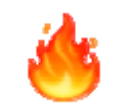
for

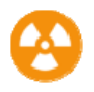
S emergency radiation or radioactivity
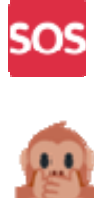

Ignoring and not doning things

Modal function \{expansion of the proposition(propositional attitude, evaluating )\}

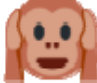

Text

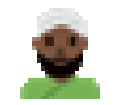

$$
\begin{aligned}
& \text { aleimamuh"( a } \\
& \text { form of } \\
& \text { customary } \\
& \text { headwear worn } \\
& \text { by Muslims) }
\end{aligned}
$$

Chalinging effect

Alarming effect

Warning effect

Informative effect

Text

Less

degree of threat

Decorative effect

$$
\text { threat }
$$

High degree of threat

Text 13: CNN,(2020, MAR 28). “ I CUESS THEY WON'T BE VOTING FOR TRUMP LIKE THEY DID IN 2016 SINCE THEY'RE LEARNIN' THE HARD WAY THAT HE AIN'T ABOUT $S H$ 으 T!! 의 "[comment, male]. You tube

Text 14:

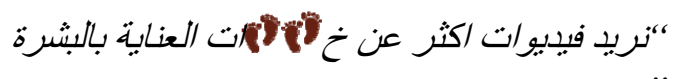

(2020,Feb 8). "We want more videos on skin care s 


\section{Macrothink}

female]. You Tube

Text 15: ABC news,(2020, Dec11). " America is reaping the () all over middle east, can anyone see this?"[comment, male]. You Tube

Text 16: NBC,(2020, MAR 24). if I get corona I get corona

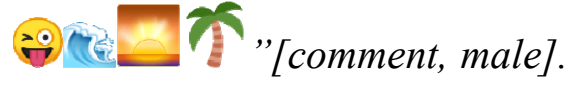
You Tube

Another function played by emoticons in iconographetic communication is a referential function, in which emoticons are used instead of a letter, parts of word or a complete word to refer to the same proposition of the physical word. In example(13), the commenter exploits the Pile of Poo $\stackrel{0}{\circ}$ emoticon instead of the letter "I" in the word shit, and the reader can easily understand the user's intention since a poo emoticons $\stackrel{0}{-}$ may be used to represent slang terms. It also conveys a sense of whimsy or silliness. Turn to example (14), the commenter involves human footsteps emoticon and repeats it twice to stand for Arabic letters " in Arabic word خطوات which means "steps" in English to replace part of the word. Moving to example(15), the employer uses a peach emoticons to replace a complet word 'wealth'. The codes of the words "reaping" and the word " middl east" help the researcher to guess the mraning of this emoticcon. The last but not the least is when the user utilises multiple emoticoms to repressent one word as in example (16). The commenter in this comment uses a wave of water , the Sunrise 2 and a palm tree $\bar{g}$ as a replacement of the word "beach". Now it is valuable to discuss the sentiment effect of the emoticons in the above mentioned examples. Beginning with example (13), the commenter uses a negative emoticon '을, with a negative message to decrease the negativity of the message. In example (14), the user blends a non- facial emoticon ' $/ \mathrm{J}$, with a positive message for increasing sentiment effects on a plain positive message. In example (15), the researcher notes that the mixture between non- facial emoticon with a negative message does not affect the sentiment of a negative message. finally, in example (16), there are positive emoticons coupled with a negative message to convey less negativity. 
Table 9. Analysis of Emoticons of Texts $(13,14,15,16)$ Following Achi's Mode

\begin{tabular}{|c|c|c|c|}
\hline Emoticons & $\begin{array}{l}\text { Physical / the } \\
\text { addresser }\end{array}$ & Psychological / the address & $\begin{array}{l}\text { Practical } \quad \text { the } \\
\text { addressee }\end{array}$ \\
\hline $\begin{array}{l}\text { Text } \\
13\end{array}$ & $\begin{array}{ll}\text { represent } & \text { feces } \\
\text { and } & \text { other } \\
\text { bathroom } & \\
\text { topics } & \end{array}$ & $\begin{array}{l}\text { Refrentail function } \\
\text { \{ replacement of a letter(i) in } \\
\text { the word "shit"\} }\end{array}$ & Chalnging effect \\
\hline $\begin{array}{l}\text { Text } \\
14\end{array}$ & Human steps & $\begin{array}{l}\text { Refrentail function } \\
\{\text { replacement of parts }(\text { و } \text { و "خطوات"\} }\end{array}$ & Informative effect \\
\hline $\begin{array}{l}\text { Text } \\
15\end{array}$ & Peach & $\begin{array}{l}\text { Refrentail function } \\
\{\text { replacement of a complet } \\
\text { word "wealth" }\end{array}$ & Informative effect \\
\hline $\begin{array}{l}\text { Text } \\
16\end{array}$ & $\begin{array}{l}\text { Water wave } \\
\text { Sunrise }\end{array}$ & $\begin{array}{l}\text { Refrentail } \\
\{\text { replacement of a complet } \\
\text { word (beach) with multible } \\
\text { emoticons }\end{array}$ & $\begin{array}{l}\text { Informative, } \\
\text { challenging effect }\end{array}$ \\
\hline & Tree & & \\
\hline
\end{tabular}

\subsection{Quantitative Analysis}

The quantitative analysis is centered first on the sentiment effect of emoticons in the corpus.

A total of 60 examples contain 131 emoticons. They are mainly divided into facial and non-facial emoticons: 53 emoticons [40.4\%] are facial and 77 emoticons [58.7\%] are non-facial. During this section, the researcher scores an emoticons and classifies them into three classes; positive, negative and neutral. Positive emoticons represent feelings and opinions like 'good', 'happy' and 'love'. Whereas negative emoticons reflect feelings and opinions like 'bad', 'sad' and 'hate'. This way, each positive emoticon in the corpus is given a score of plus one [+1] and each negative emoticon is given the score of minus one [-1].

Emoticons have a neutral sentiment take the zero score by default is objectivity score. 


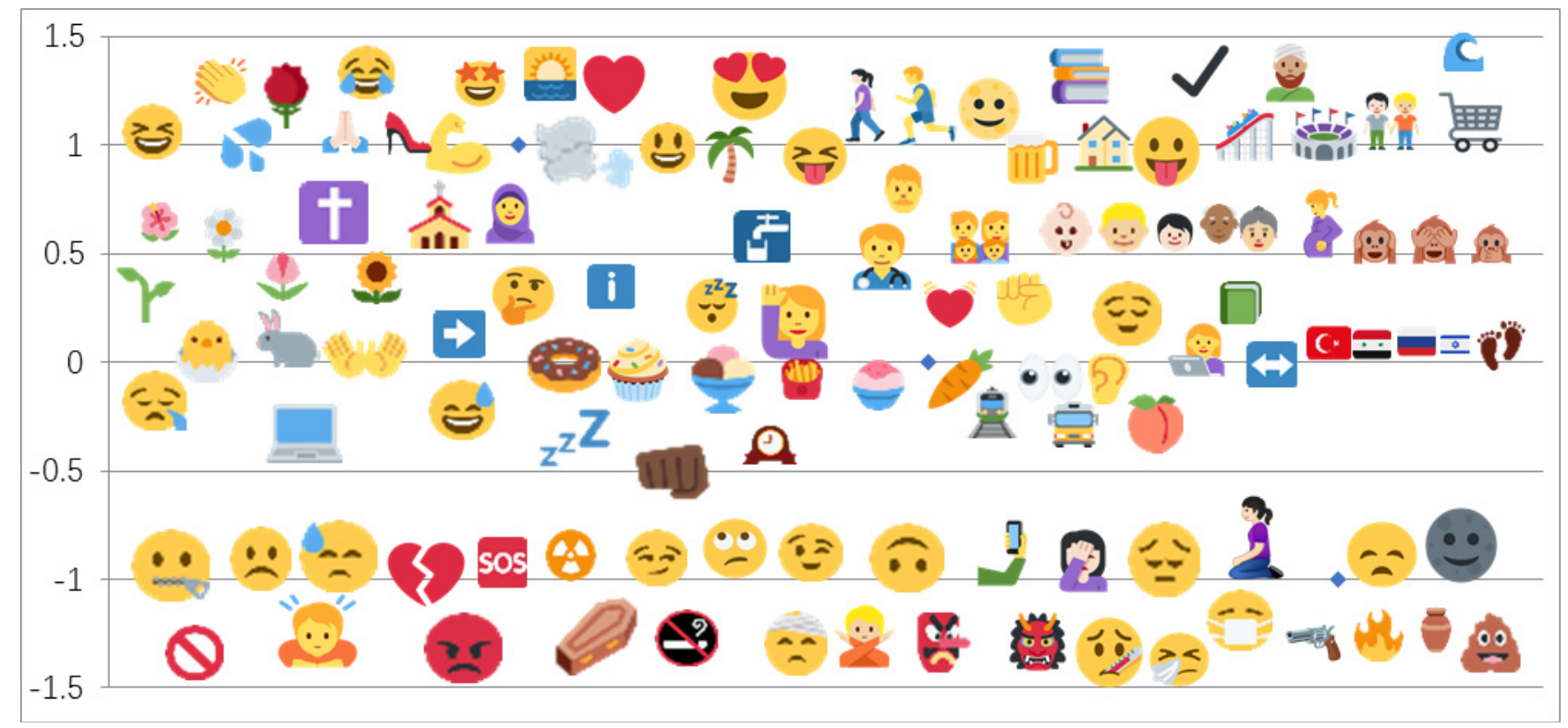

Figure 2. The sentiment score of emoticons without text

Figure (2) shows that a total of 131emoticons, 41 emoticons [31.2\%] are positive, 42 emoticons [32.2\%] are negative and 48 emoticons [36.6\%] are neutral.

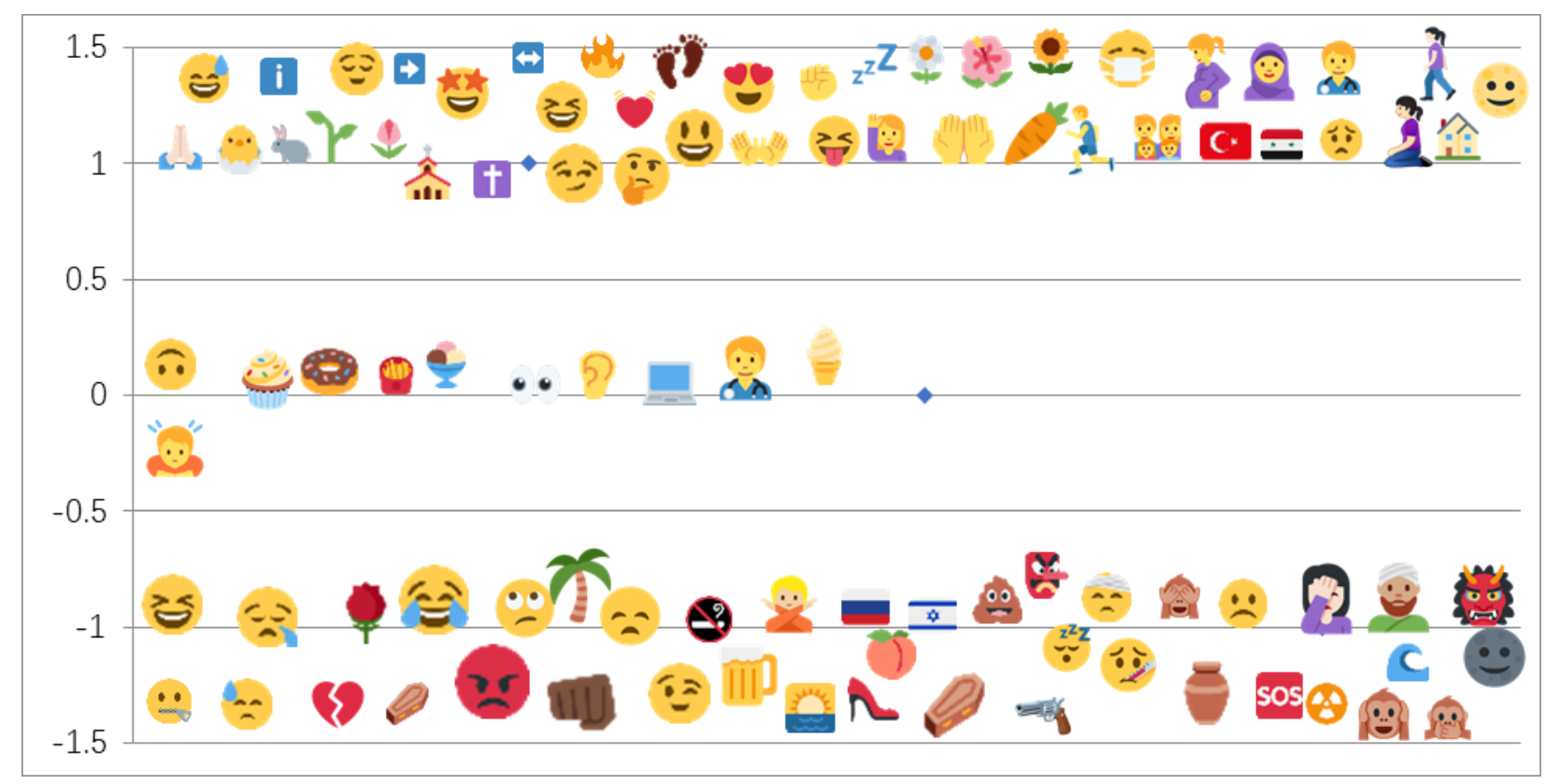

Figure 3. The sentiment score of emoticons with text

Figure (3) shows the sentiment results obtained from scoring the emoticons with text characters. 100 emoticons [76.3\%] are utilised with text classify as follows: 45 emoticons [45\%] are positive, 48 emoticons [48\%] are negative and 7 emoticons [7\%] are neutral. 


\section{MInstitute Macrothink $_{\text {Int }}$}

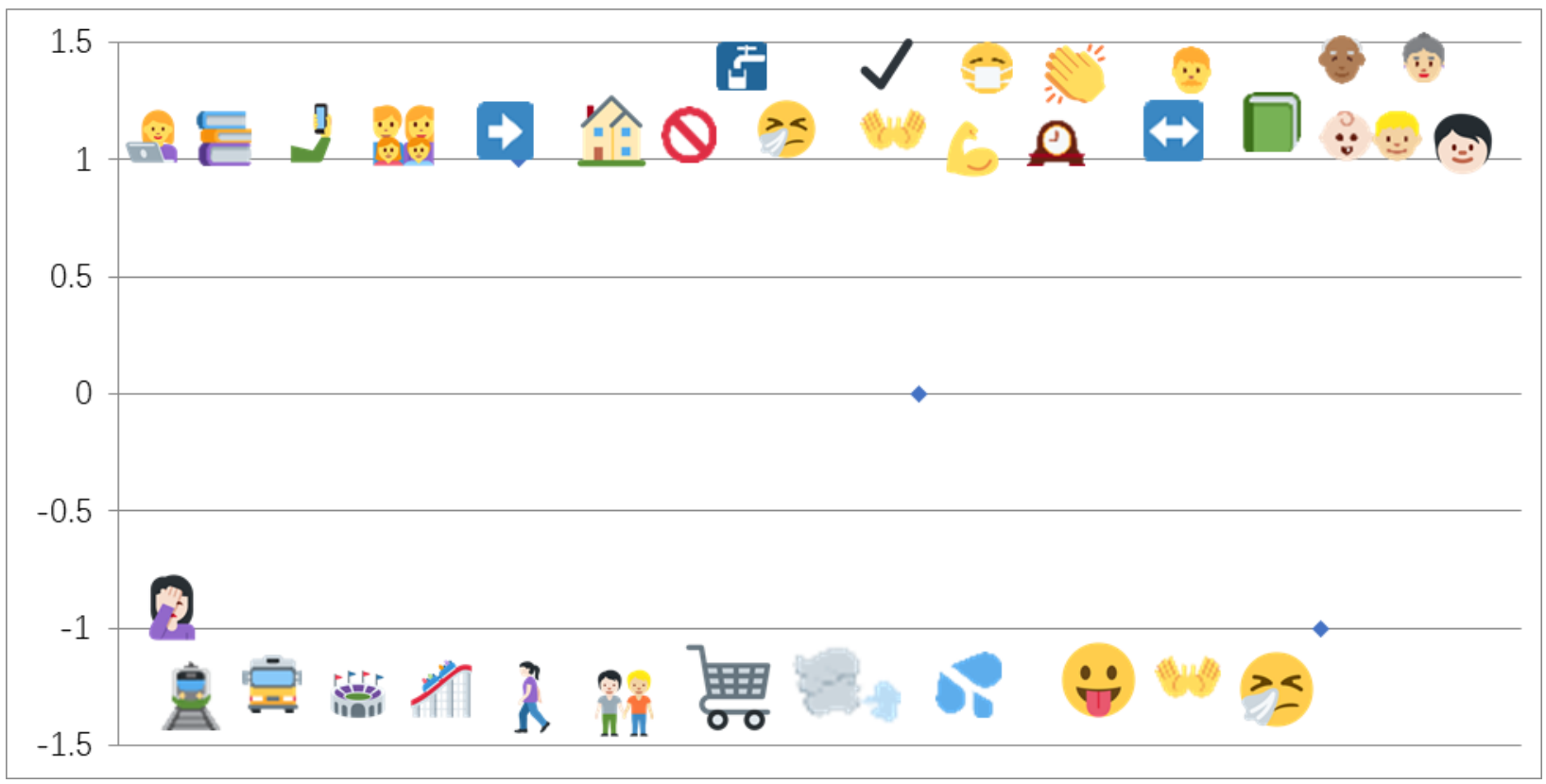

Figure 4. The sentiment score of coupled emoticons

Figure (4) shows the result of scoring the data by taking emoticons characters in consideration. In other words, this chart displays the sentiment of emoticons combine with other emoticons without any verbal contents. A total of 31 emoticons [23.6\%] come with each other in 4 examples as a complete sentences. 18 emoticons [58.1\%] are positive and 13 emoticons [41.9\%] are negative. There is not any neutral emoticon in this chart.

What is observed from the sentiment analysis of emoticons is that considering emoticons in sentiment effect of examples help to improve overall sentiment scores. While emoticon characters are used for expressing both negative and positive opinions, the usage of emoticons with text appears to improve the expressivity and an overall sentiment scores of positive and negative opinions relatively more than the neutral opinions.

Moving to the second part of quantitative analysis, the researcher notes the following points: First, it is observed that a large part of users [93.3\%] prefer texts where emoticons are occasionally or frequently used with texts. But only [6.6\%] participants prefer the emoticon only usage. Reasonably, the excessive usage of emoticons alone without text has many disadvantages. Although emoticons are powerful in expressing emoticons, they lack flexibility and accuracy in conducting complicated ideas. The information exchanges via emoticons only is hardly enough for most communication tasks.

Second, factors which influence the use of emoticons that have been investigated here include the users' gender and native language. The results show there are a significant differences in value and number of emoticons between males and females who use emoticons. A total of 219 emoticons in 60 examples, females utilise 96 emoticons[43.8\%] in 22 examples. Whereas males use 83 emoticons [37.8\%] in 28 examples. as far as the numbers of examples are concerned, the results suggest the number of emoticons which are utilised by females are much larger than males. 
Based on the diversification and the origin of the users, the researcher classifies them into two major categories: westerners(English/European language speakers) and Arabs (Arabic language speakers), since they represent the two culture groups. Another reason for partitioning users this way is that the difference between the two categories are significant, while people in the same category share very similar cultural backgrounds, especially the methods of communications. It is valuable to note, the researcher chooses 14 examples from 46 examples that have been written in English language as the corpus have only 14 examples written in Arabic language. Also in order to get reliable results. 27.8\% emoticons are used by Arabic speakers in 14 examples. while $32.8 \%$ emoticons are used by English speakers. The difference is not very significant. Indicating that emoticons itself in contrast to their interpretations are not affected by specific cultural backgrounds.

\section{Conclusions}

All these examples of texts appearing help to make the situation that they depict more detailed and easier to comprehend. In all these cases, they play the role of a supplementary explanation. However, it is necessary, for the meaning of the signs to create some kind of mutual understanding between sender and receiver. Though, the additional texts serve the function of 'determining' the specific emotion or action of emoticons. Their meaning changes accordingly from the representation of facial expressions to the representation of actual situations. If simple emoticons are contextualisation cues substituting the writer's absent body, emoticons within text do not evoke that body but the entirety of the communicational situation. They can thus facilitate a contextualisation within a represented, three-dimensional space of communication.

Emoticon has two main functions: The modal and referential functions. However, their referential function is not solely restricted to the replacement of nouns; the analysis of iconographetic communications has shown that pictorial characters can also replace verbs, adjectives, and even propositions as a whole. The respective substitution does not just take place at word level; individual elements of compounds or even the noun basis in the suffix derivation can be replaced with emoticon too. Pictorial characters can also be used as allographs at the level of the individual graphs (as a substitution of letters, sometimes without any pictorial meaning). Furthermore, the use of several emoticon can evoke frames and these frames can, in turn, act as word substitutes.

The results suggest the subtle differences between emoticons types, such as negative emotions are more intended to be used than positive emoticons to express sentiment, and neutral emoticons are the most proper to express irony. From a message recipient perspective, it is studied how recipients feel about the sentiment conveyed by emoticons. Instead of separating emoticons and verbal messages, they are treated as a whole. the results uncover the divergent sentiment effects of emoticons: positive emoticons do not affect the sentiment of plain positive verb messages, nor do negative emoticons affect the sentiment of plain negative messages. In addition, the results suggest that the duplicate usage of emoticon do not express more intense sentiment than single emoticons in most cases.

\section{References}

Achi, S. (2010). Third international conference on advances in computer- human interaction, 


\section{Macrothink}

IEEE computer society (pp.1-6). Washington: DC.

Adegbija, E. (1999). Tidbits on discourse analysis and pragmatics. In E. Adegbija (Ed.), The English language and literature in English (pp. 186-205). Ilorin, MEL Department: University of Ilorin.

Baruah, T. (2012). Effectiveness if social media as a tool of communication and its potential for technology enabled connections: A micro level study. Journal of scientific research publication, 2(5).

Bignell, J. (2002). Media semiotics: An introduction. Manchester University Press.

Creswell, J. W. (2014). Research design: Qualitative, quantitative and mixed methods approaches (4th ed.). Thousand Oaks: Sage.

Crystal, D. (2010). The Cambridge Encyclopedia of language. (3rd Edition). Cambridge University Press.

Darics, E. (2010). Politeness in computer-mediated discourse of a virtual team. Journal of Politeness Research, 6(1), 129-150. https://doi.org/10.1515/jplr.2010.007

Denzin, N., \& Lincoln, Y. (1994). Handbook of qualitative research, thousand oaks (Calif). Sage.

Devellis, J. (1991). Theory and application. Sage.

Eco, U. (1976). A theory of semiotics. Indiana University Press. https://doi.org/10.1007/978-1-349-15849-2

Leech, G. N. (1983). Principles of pragmatics. Longman.

Nishimura, Y. (2015, October 21-24). A sociolinguistic analysis of emoticon usage in Japanese blogs: A variation by age, gender and topic. Association of Internet Researchers. USA.

Potts, A. (1996). Sign. In R. Nelson \& R. Shiff, (Eds.), Critical terms for art history, london and chicago. University of Chicago Press.

Tian, Y., Galery, T., Dulcinati, G., Molimpakis, E., \& Sun, C. (2017). Facebook Sentiment: Reactions and Emojis. Proceedings of the Fifth International Workshop on Natural Language Processing for Social Media. UK. https://doi.org/10.18653/v1/W17-1102

The New Lexicon Webster's Encyclopedia Dictionary of the English Language. (1993) Lexicon Publications Inc.

The Oxford English Dictionary (1989). (2nd ed. Vol LX). Clarendon Press.

Yule, G. (1996). Pragmatics. Oxford University Press.

Wales, K. (1989). A Dictionary of Stylistics. Longman.

Walther, J. B., \& D'Addario, K. P. (2001). The Impacts of Emoticons on Message Interpretation in Computer-Mediated Communication. SSCR, 19(3), 324-47. https://doi.org/10.1177/089443930101900307 
Appendix

Appendix A. Screenshots of English Comments and Tweets

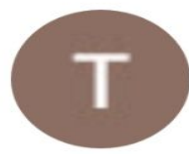

Talha Baloch $\cdot 2$ weeks ago

Poor turkish jihadi soldiers

1

It was conspiracy theory when we

were saying the mass graves in

chaina, now Washington post

publishes and it's real news. 0

$\vdots$

E

16

(2)

(n)

1 second ago

a) 3 OMG THIS MAKE ME LAUGH SOOO HARD

-6

Bill Bailey - 1 month ago

The UN is a paper Tiger.

NATO is a weekend sports club.

Everyone hides behind lawyers.

Planet Earth, safe in their hands $\theta \Leftrightarrow$

111 gा 2

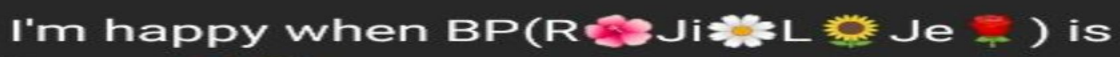
happy st

IS 28 ए

Marky Mark - 3 days ago

Burn the dead bodys, less diseases and takes up less land space $0 \circlearrowleft \circlearrowleft, 00$

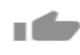




\section{Macrothink}
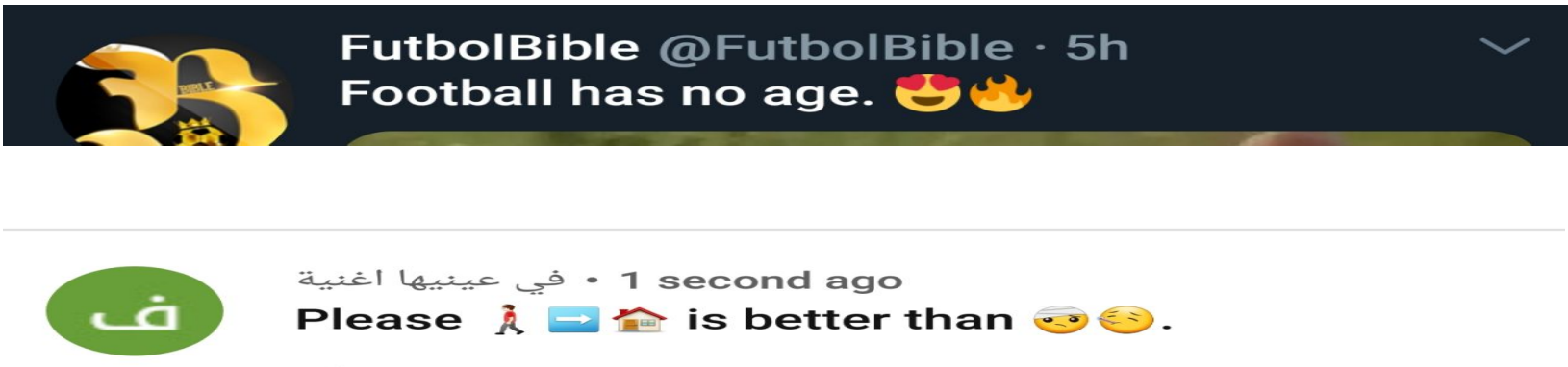

- 1 second ago

Please $R \rightarrow$ is better than $\Theta \Theta$.

16

Q1

$\equiv$

¿】 UNFPA Retweeted

WHO Yemen 2 @WHOYemen.3d

WHO\&@UNFPA_Yemen partner with the support of @UAEAid to build the capacity of health systems and community-based services to ensure access and increased availability of emergency reproductive health services for women 9

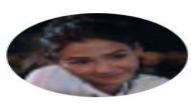

Aybu Fans - 1 month ago

Poor Syria people

Everybody come to them and do the sheet

Syria became a place for war to USA, Turkey, Russia, EU and others. $\sigma$

It's easy to talk about it when you are far from fire and death. sos

$100 \%$ they are doing the war for money and political dominance

Look at this hypocrite attitude of the UN.

\section{Mohammed.A.W محمد عبد... 14 Apr

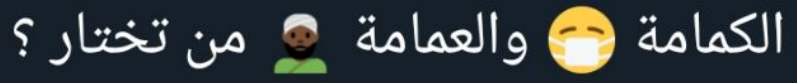 لو خيروك بين

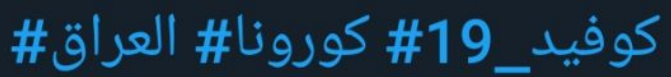


- 1 second ago

كوريا الشمالية تهدد العالم بالاسلحة النووية تِ وتركيا تهدد

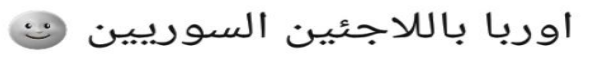

1

(1)

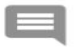

0 O SNOOPY SNOOP \#1 - 9 minutes ago

I GUESS THEY WONTTBE VOTING FOR TRUMM

LIKE THEY DID IN 2016 SINCE THEYRE

LEARNIN: THE HARD WAY THAT HE AINTT

ABOUT SIHETTII Uु

109

杂条木涁 - 3 months ago

America is reaping the $d$ all over middle east, can anyone see this?

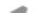

15 minutes ago

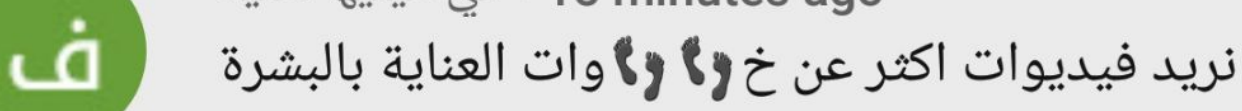
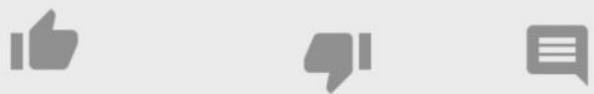

Tater Tot 2020 Üwú - 23 hours ago

If I get Corona I get Corona

\#SpringBreak2020

151

ra

$\equiv$ 


\section{Macrothink}

Education and Linguistics Research

ISSN 2377-1356 2020, Vol. 6, No. 2

Appendix B. Expert Evaluation Report

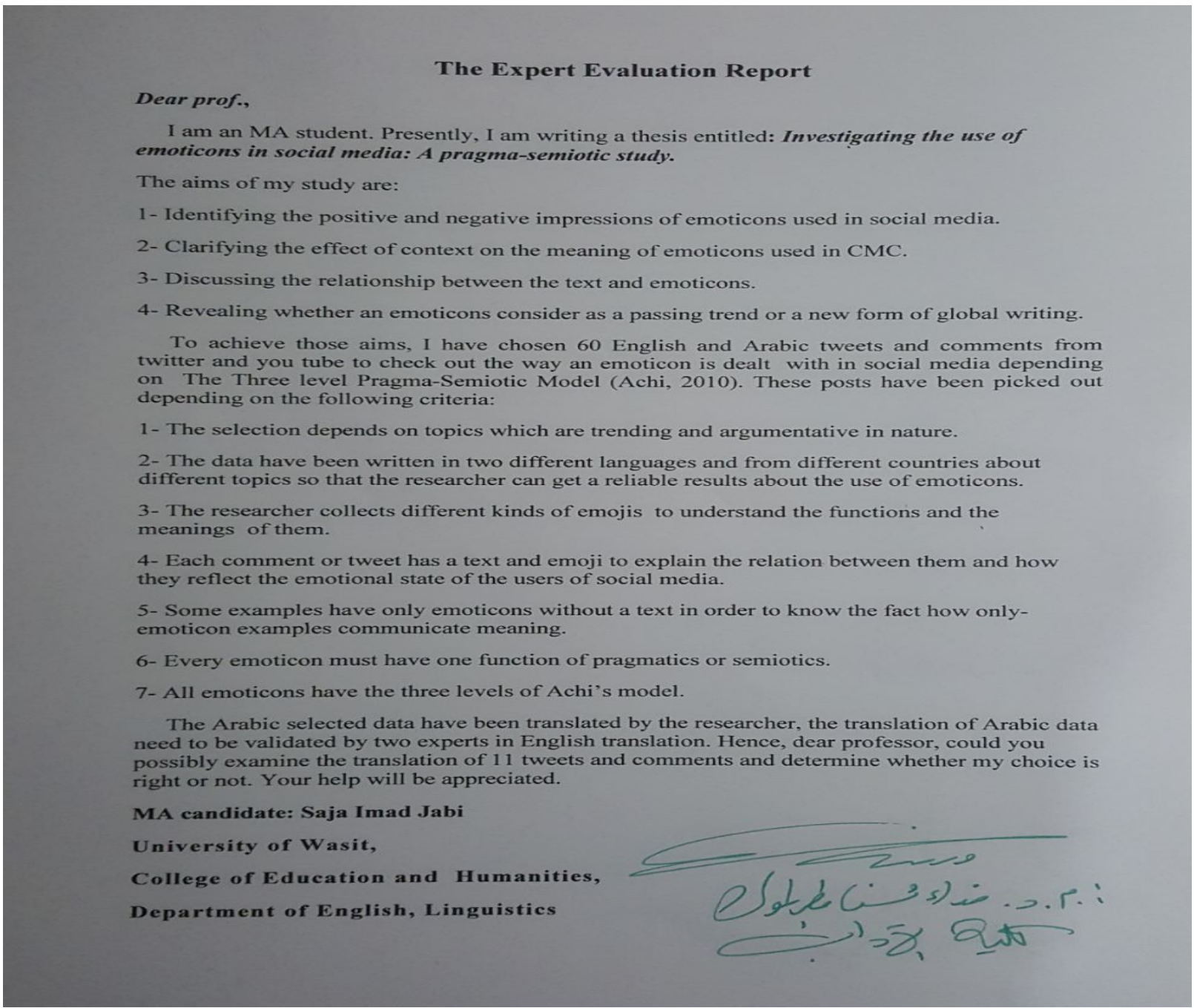

\section{Copyright Disclaimer}

Copyright reserved by the author(s).

This article is an open-access article distributed under the terms and conditions of the Creative Commons Attribution license (http://creativecommons.org/licenses/by/4.0/). 